\title{
A função educadora e a dimensão ética da natureza: indagações para uma proposta curricular
}

Ademar Heemann*

\section{O problema}

A interrogação diminui o nosso sentimento de certeza sobre como as coisas são, e aumentam o nosso conhecimento de como elas podem ser.

\section{Russel}

No exame da dimensão axiológica da natureza, pretendo dialogar com discurso naturalístico a respeito dos valores éticos em face de sua importância na determinação dos modelos do comportamento humano. Presumo que a compreensão da problemática contida nesse diálogo implica na análise tanto das recorrências naturalistas da legitimação ética como da própria origem e desenvolvimento ontogenético do senso moral. ${ }^{1}$

Esse intento está em consonância com o projeto mais abrangente da Universidade comprometida com a filosofia de atuação dos Programas Governamentais de incentivo à interdisciplinaridade no trato do ambiente $\mathrm{e}$

* Professor do Departamento de Teoria e Fundamentos da Educação, Universidade Federal do Paraná.

1 HEEMANN, A. Natureza e ética: Dilemas e perspectivas educacionais. Curitiba : Ed. da UFPR., 1993. p. 143. 
de sua apropriação. ${ }^{2}$ Para tanto, a Universidade Federal do Paraná se propõe a implantar cursos de pós-graduação amparados em metodologias interdisciplinares, contexto onde se insere a presente proposta curricular.

\section{Indagações}

Quais os fundamentos da tese que estabelece o "século XXI como o século da mudança do paradigma econômico para o paradigma ecológico?

Qual o papel da educação no processo de reconhecimento de valores?

Sob que referencial teórico pode ser compreendido o processo contemporâneo de valoração da natureza?

Como é possível legitimar uma ética da sobrevivência?

Quais as implicações éticas do discurso naturalístico contemporâneo sobre a origem da moralidade?

Quais as recorrências contemporâneas ao conceito de natureza para a fundamentação ou justificação dos princípios éticos?

Quais os fundamentos do discurso naturalista contemporâneo para a transmutação de um valor fatual (natureza) para um valor ético?

É possível o convívio entre a moralidade legal e a valoração da natureza?

Qual o referencial epistemológico e a dinâmica curricular de um curso que contempla a questão do meio ambiente sob uma perspectiva psicossocial?

\section{Justificativa}

\section{Relevância operativa}

Torna-se oportuna e relevante a implementação desse projeto em face das perspectivas de geração de novos conhecimentos e possibilidades de intercâmbio com instituições do país e do exterior que desenvolvem atividades congêneres.

Com relação ao aspecto teórico, o projeto acena com adições ao

2 Cf. PADCT - II. Subprograma de Ciências Ambientais - CIAMB. Doc. Básico. out. 1990. 
conhecimento, beneficiando a Instituição Universitária devido à aplicabilidade do saber adquirido, nos cursos de graduação e pós-graduação.

\section{Relevância contemporânea}

Essa investigação ajusta-se plenamente ao estado atual do problema ético-ambiental, respondendo a uma necessidade da época. Está inserida entre as prioridades dos Planos Governamentais, pois, como apregoa o Subprograma de Ciências Ambientais do PADCt-CIAMB. ${ }^{3}$

Urge buscar e implantar uma nova ordem econômico-social. Isso necessariamente, pressupõe cooperação humana fundada numa ética de sobrevivência. Esta tarefa só poderá ser cumprida com a conjugação de certos fatores: consciência social, vontade política, disponibilidade de conhecimento científico e geração de tecnologias adequadas.

Relevância Humana

A temática ambiental numa concepção mais abrangente contempla o problema da saúde, da miséria, da pobreza cognitiva e fatores da injustiça. Por sua vez, a reflexão axiológica como processo emancipatório beneficia o homem, pois desenvolve aquelas atitudes próprias da autonomia moral em que $o$ indivíduo reconhece valores e compreende as relações mútuas entre ele e o meio circundante.

\section{Procedimentos metodológicos}

\section{Esquema Operacional}

O esquema operacional dessa investigação consiste dos seguintes procedimentos básicos:

- Delimitação das questões de pesquisa.

- Discussão com interlocutores e reajustes na investigação.

- Encontros de trabalho com estudiosos de temas específicos.

- Análise dos programas curriculares de outras instituições.

- Análise de documentos, relatórios e publicações representativas na atualidade.

- Análise de conteúdos. 
- Elaboração de relatórios para a área acadêmica (proposta curricular aos cursos de pós-graduação e outras comunicações).

Esses procedimentos se assentam no processo de construção teórica de um paradigma para compreender e explicar a questão ambiental. Os pressupostos conceptuais dessa construção e subjacentes na execução da pesquisa são comentados a seguir.

\section{Esquema Conceptual}

Tal construção tem como marcos de referência a visão da interdisciplinaridade (enfoque epistemológico) e a démarche da justificação ética a partir de proposições refutáveis que levam em conta a relatividade das circunstâncias nas quais vive o homem (enfoque filosófico).

\section{Enfoque Epistemológico}

É evidente que a complexidade dos problemas aqui propostos exigem conhecimento mais amplo. Esse conhecimento, porém, "se encontra pulverizado sob múltiplas disciplinas que, segundo Gusdorf, brincam constantemente com a realidade humana e se recusam a considerá-la em sua integralidade, porque põem sobre os olhos a venda de suas epistemologias particulares. Mas está ao alcance do educador uma atitude que se funda na revelação natural da unidade humana. Refiro-me à consciência interdisciplinar. Assegurado por uma epistemologia da convergência, o educador, não obstante as limitações de sua disciplina e de seu próprio conhecimento, poderá imprimir uma nova dimensão ao seu trabalho ao inseri-lo em um núcleo maior (de) compreensão da realidade. Em conseqüência, problemas não resolvidos, mas colocados sob perspectiva, permanecerão fecundos para serem retomados nas diferentes oportunidades educacionais." ${ }^{4}$

\section{Enfoque Filosófico}

O enfoque filosófico encontra na interdisciplinaridade a base metodológica para a abordagem da démarche da justificação dos princípios éticos. A justificação teórico-pragmática de uma norma e 0 ato de mostrar que a um certo respeito ela é favorável ou compatível com a satisfação de um deside-

4 GUSDORF, Georges. Interdisciplinaridade. Ciências Humanas, I, 2, p. 1977; Cf. HEEMANN, op. cit. p. 14. 
ratum de determinada unidade social em determinada circunstância. Trata-se de uma linha referendada por Saches Vazques e Bunge que se apresenta como alternativa ao objetivismo absoluto e ao subjetivismo extremado no campo axiológico. ${ }^{5}$ Procuro amparar essa estrutura de legitimação nos seguintes pressupostos:

- a "reciprocidade de intenções" e a universalização normativa pelo assentimento ao imperativo categórico de Kant entre todos aqueles que se decidiram pela busca de uma verdade consensual; ${ }^{6}$

- o "princípio de transmutação normativante" proposto por Ladriere como forma de mediação para um enunciado galgar o nível axiológico; ${ }^{7}$

- a "estrutura do diálogo" pois, nos termos de Gadamer, a compreensão revela uma estrutura de diálogo, isto é, para compreender deve-se estar disponivel para que os pontos de vista e indagações se completem uma confluência de crescimento contrária às práticas persuasórias. ${ }^{8}$

5 Cf. Bunge, Mário. Ética Y ciência. Buenos Aires, Siglo Veinte, 1972. p. 64; SANCHEZ VAZQUEZ, Adolfo. Ética. Rio de Janeiro : Civilização Brasileira, 1969; p. 223-27; cf. Heemann, op cit. p. 43, 54.

6 Sobre a teoria moral de Habermas, cf. Siebeneichler, Flávio B. A Teoria moral de UERGEN HABERMAS. Boletim de Filosofia e Ciências Sociais, v.5, p.11-19, 1988; ver também HABERMAS, Juergen. Moralbewusstsein und kommujnikatives handeln. Frankfurt am Main, Suhrkamp, 1991; cf. Heemann, op. cit. p. 151.

7 LADRIERE, Jean. La biologie neut-elle fonder une morale? Revue Reseaux, 20-21: 83-116, 1973; Cf. Moser, Alvino. Ya-t-il un fondament scientifique de étique? Louven, 1974. These, Doctorat, Université de Louven; cf. Heemann, op. cit. p. 52.

8 GADAMER, Hans-Georg. Wahrheit und methode. Tuebingen, J. C., Mohr, 1965, p. 345; cf. Heemann, op. cit. p. 131. 


\section{REFERÊNCIAS BIBLIOGRÁFICAS}

BIRNBACHER, D. ; HOERSTER N. Texte zur Ethik. Muenchen, Deutscher Taschenuch Verlag $\mathrm{GmbH} \& \mathrm{Co}$. KG.

BUNGE, Mário. Ética y ciência. Buenos Aires : Siglo Veinte, 1972.

GADAMER, Hans-Georg. Wahrheit und methode. Tuebingen, J. C. B. Mohr, 1965.

GUSDORF, Georges. Interdisciplinaridade. Ciências Humanas. I, 2, p.13, 1977.

HABERMAS, Juergen. Moralbewusstsein und kommunikatives handeln. Frankfurt am Main, Suhrkamp. 1991.

HEEMANN, A. Natureza e ética: dilemas e perspectivas educacionais. Curitiba : Edit. da UFPR, 1993.

Da biologia à ética: uma análise do discurso construtivista de Maturana. Kassel, Gesamthoschule Kassel Universitaet, Wissenschaftliches Zentrum Mensch - Umwelt - Technik, 1993. Mimeogr.

IBAMA. Diretoria de Incentivo à Pesquisa e Divulgação. Seminários Universidade e Meio Ambiente: Documentos Básicos. Brasília, 1989.

JONAS, Hans. Das Prinzip Verantwortung: Versuch einer Etnia fuer die tecnologische Zivilisation. Frankfurt am Main, Suhrkamp Taschenbuch Verlag, 1984.

LADRIERE, Jean. La biologie peut-elle fonder une morale? Revue Reseaux. 2021:83-116, 1973.

MORALITY as a biological phenomenon. Berkeley, University of California Press. 1980.

MOSER, Alvino. Ya-t-il un fondament scientifique de étique? Louven, 1974. Theese. Doctorat. Universite de Louven.

PADCT - II. Subprograma de Ciências Ambientais - CIAMB. Doc. Basico. out. 1990. SANCHEZ VAZQUEZ, Adolfo. Ética. Rio de Janeiro : Civilização Brasileira, 1969. SIEBENEICHLER, Flávio B. A teoria moral de Juergen Habermas. Boletim de Filosofia e Ciências Sociais. v.5, p.11-19, 1988. 